\title{
Joko matematikoen hurbilketa: kasu diskretua
}

\author{
(Mathematical Games Approximation: the Discrete Case) \\ Josu Doncel Vicente
}

Matematika Aplikatua eta Estatistika eta Ikerkuntza Operatiboa Saila UPV/EHU

josu.doncel@ehu.eus

DOI: $10.1387 /$ ekaia.17757

Jasoa: 2017-04-03

Onartua: 2018-05-16

Laburpena: Joko-teoriaren helburua eragile arrazioanalen portaera estrategikoak aztertzea da. Eragile kopurua oso handia bada, batez besteko eremuko jokoak joko lehiakor finituen hurbilketa onak dira eta, hori dela eta, biziki ikertuak izan dira azken urteotan. Hala ere, literaturan, artikulu gutxitan onartzen da jokalarien akzio-espazioa diskretua dela. Eredu horiek dira, hain zuzen ere, gure ikerketan aztertzen ditugunak. Jokalariak simetrikoak direla onartuko dugu, baita jokalarien kostu-funtzioa eta dinamikak jarraituak direla ere. Artikulu honetan erakutsiko dugu badela beti oreka bat batez besteko eremuko joko horietan.

Hitz gakoak: Joko-teoria, batez besteko hurbilketa, kasu diskretua.

Abstract: Game-theory is the set of mathematical tools to study the rational behavior of interacting agents or players. When the number of players is large, mean-field games have been proposed as an approximation of non-cooperative finite games. Contrarily to most of the literature in this area, we analyse mean-field games when the number of possible actions that players can take is discrete. We consider that players are symmetric and that the cost function and the dynamics of the players are continuous. In this article we show that a solution of these type of mean-field games always exists.

Keywords: Game-theory, mean-field approximation, discrete case. 


\section{SARRERA}

Batez besteko jokoen teoria 2007. urtean sortutako matematika-arloa da $[7,8,9]$. Duela gutxikoa da, hortaz; hala ere, oso garrantzitsua bilakatu da, bi arrazoirengatik: batetik, zenbait arlotan ematen delako - ekonomian edo biologian besteak beste - eta, bestetik, joko-teoria klasikoarekin alderatuta, eredu sinpleak direlako batez besteko jokoak. Hori dela eta, azken hamarkadan batez besteko jokoen inguruan egiten ari den ikerketa kopurua oso handia da.

Artikulu honen helburua da autoreek azken urteotan nazioarteko ikertzaileekin egin duten ikerketaren laburpen bat egitea. Lehenik, autoreen eredua joko-teoria klasikoaren eta batez besteko jokoen teoriaren testuinguruan non aurkitzen den azalduko da; horretarako, gero, joko-teoriaren zein batez besteko joko-teoriaren errebisio bibliografiko bat egingo da. Bukatzeko, auteoreek beren ikerketan lortutako emaitzak aurkeztuko dira.

\section{JOKOEN TEORIA LEHIAKORRA}

Joko-teoria indibiduoen portaera estrategikoen analisia helburu duen matematikaren arloa da. Joko-teoriaren bidez, indibiduo batek (jokalari deritzonak) hartu beharreko erabakiak ikertzen dira, gainerako indibiduo guztiek zer egiten duten kontuan hartuz. Hori dela eta, gaiari buruzko literaturan erabakien teoria izena ere ematen zaio maiz.

John F. Nash matematikaria jotzen da joko-teoria lehiakorraren sortzailetzat. Izan ere, berak edo-zein joko finituk soluzio bat duela frogatu zuen; Nash-en oreka deritzo soluzio horri. Emaitza horri esker, Nobel saria irabazi zuen 1994. urtean Nashek. Emaitza hori iraultza izan da; matematikan ez ezik, beste hainbat arlotan ere besteak beste, politikan, ekonomian, biologian eta telekomunikazioetan.

Joko lehiakorren osagaiak hauek dira:

- jokalari-espazioa, hau da, erabakiak hartzen dituzten eragileak;

- akzio-espazioa, hots, eragileek har ditzaketen erabakiak, eta

- agente baten kostu-funtzioa, alegia, eragile batek erabaki bat hartzen duenean jasotzen duen balioa, beste jokalarien erabakien mendekoa.

Argiago ikusiko dugu zer den joko bat presoen dilema izeneko adibidea erabiliz: Bi preso kartzelan daude, eta poliziak egia jakin nahi du gertatutakoaz. Presoak gela banatan daude eta ezin diote elkarri hitz egin. Poliziak preso bakoitzari bi aukera ematen dizkio: isilik egotea edo polizia laguntzea. Horrela,

- bi presoek polizia laguntzen badute, bakoitzak 4 urte igaroko dituzte kartzelan; 
- batek laguntzen badu eta bestea isilik geratzen bada, laguntzen duena libre geratuko da, eta besteak 7 urte egon beharko du kartzelan;

— biek isilik badiraute, bakoitzak 2 urte igaroko ditu kartzelan.

Presoen dileman, beraz, bi jokalari daude, eta jokalari bakoitzaren akzio-espazioa da isilik egotea edo polizia laguntzea. Kostu-funtzioa preso bakoitzak kartzelan eman beharko duen denbora da, eta bi presoen erabakien araberakoa da - argi ikusten da - . Presoen helburua da kartzelan ahalik eta denbora gutxien igarotzea; horretarako, isilik egotea edo polizia laguntzea aukeratu behar dute (elkarri kontsultatu gabe). Aurretik erabakirik adostu ez dutela onartuta, zer egingo dute presoek?

Egoera bat egongo da non presoek ez duten bere erabakia aldebakarrez aldatzeko interesik; izan ere, presoetako batek bere akzioa aldatzen badu, denbora gehiago igaroko du kartzelan. Egoera hori-biek polizia laguntzaren aukera, hain zuzen-joko honen Nash oreka (edo soluzioa) izango da. Izan ere, egoera horretan, bi presoak lau urtez egongo dira kartzelan. Gainera, presoetariko batek bere erabakia-polizia laguntzea, alegia-aldatzen badu (isilik geratuz), zazpi urte igaroko ditu kartzelan. Hortaz, biek polizia laguntzen badute, ez dago presorik aldebakarreko erabaki aldaketa eginez onura izango duenik. Hortaz, Nash-en oreka da.

\section{BATEZ BESTEKO JOKOEN TEORIA}

Nash-en orekaren kalkulua problema PPAD-osatua dela frogatu dute orain dela zenbait urte [1]. Horrek esan nahi du Nash-en orekaren kalkulua ezinezkoa dela jokalari kopurua oso handia bada. Arazo hau gainditzeko, Nash-en orekaren hurbilketak garatzen ari dira matematikariak azken urteotan. Batez besteko eremuaren teoria orain dela mende bat baino gehiago erabili zen lehen aldiz sistema estokastikoen hurbilketa egiteko. Harrezkero, ikerketa asko egin da prozesu estokastikoen hurbilketaren inguruan, eta batez besteko eremua hurbilketa ona dela argi dago. Batez besteko eremuan oinarritutako ideiak joko-teorian erabiltzea, Lions eta Lasry matematikariek proposatu zuten, eta batez besteko eremuko joko-teoria sortu. Eredu honetan, jokalari kopurua infinitua da eta, hori aintzat hartuta, beti oreka bat existitzen dela frogatu zuten. Lionsen eta Lashryren soluzio horrek, batez besteko eremuko oreka deritzonak, zenbait abantaila ditu: batetik, haren kalkulua oso erraza da, eta, bestetik, Nash-en orekaren hurbilketa ona da jokalari kopurua handia bada.

Batez besteko jokoen literaturan aurkitu ditugun artikulu gehienetan akzio-espazio jarraitua ikertzen da; hau da, eredu horiek onartzen dute jokalariek har ditzaketen akzioak espazio jarraitu batean daudela, $[0,1]$ tar- 
tean adibidez. Horrela, batez besteko eremuko jokoa ebazteko, HamiltonJacobi-Bellmann ekuazioa eta Focker-Planck ekuazioa erabili behar dira. Horiek deribatu partzialeko ekuazioak dira, eta, normalean, oso zaila da haien soluzio analitikoa aurkitzea.

Gure ikerketan, ordea, akzio-espazioa diskretua dela joko dugu, eta, ekuazioak ebazteko, Markov-en erabakitze-prosezuen teoria erabiliko ditugu. Hori kontuan harturik, batez besteko eremuko joko desberdina lortu dugu. Horretan, Hamilton-Jacobi-Bellmann ekuazioa Bellmann ekuazio bilakatzen da, kasu diskretuan, eta Focker-Planck ekuazioa, ordea, Kolmogorov ekuazio (erreferentzietan agertzen den Putermanen liburua gomendatzen dugu Markoven teorian sakontzeko interesa duen irakurleari [11]).

Gure ikerketan aztertu ditugun ereduak oso orokorrak dira; izan ere, hurrengo atalean ikusiko dugun moduan, hipotesi gutxi kontuan hartuko dugu. Horren ondorioz, gure emaitzak erabiliz, sistema konplexu asko gure azter daitezkeela uste dugu. Hurrengo atalean gure ikerketan garatutako teoriaren kasu partikular bat ikusiko dugu. Kasu gehiago irakurri nahi dituen irakurleari [2] artikulua irakurtzea gomendatzen diogu.

\section{TEORIA OROKORRAREN KASU PARTIKULARRA}

\subsection{Batez besteko jokoaren deskribapena}

Jo dezagun jokalari homogeneoz osaturiko populazio bat dugula eta jokalari kopurua infinitua dela. Jokalariek, denbora aurrera joan ahala, erabaki berekoiak hartzen dituzte. Denbora funtzio jarraitutzat joko dugu. Jokalarien estatu-espazioa $\mathcal{S}=\{1, \ldots, \mathcal{S}\}$ da; hots, edozein unetan jokalari bakoitza $i$ estatuan dago, edo, beste era batean esanda, $i \in \mathcal{S}$. Jokalariek akzioak har ditzakete, eta, hartutako akzioen arabera, beste estatu batera mugitzen dira. Akzio-espazioa $\mathcal{A}=\{1, \ldots, \mathcal{A}\}$ da.

Jokalari baten estrategia funtzio neurgarria da: $\pi: \mathcal{S} \times \mathbb{R}^{+} \rightarrow \mathcal{P}(\mathcal{A})$, non $\mathcal{P}(\mathcal{A})$ probabilitate-bektorea den $\mathcal{A}$ multzoan ( $\mathcal{A}$ finitua denez, $\mathcal{P}(\mathcal{A})$ simplex bat da). Horrek esan nahi du $i \in \mathcal{S}$ estatuan dagoen jokalari orori une orotan ( $t \geq 0$ izanik), $\pi_{i}(t)$ probabilitate-bektore bat dagokiola. Horrela, $\pi_{i, a}(t)$ da jokalari batek $i$ estatuan $t$ denboran $a$ akzioa aukeratzeko probabilitatea. Gainera,

$$
\forall t \geq 0, \forall i \in \mathcal{S}, \quad \sum_{\alpha \in \mathcal{A}} \pi_{i, \alpha}(t)=1
$$

Akzio bat determinista da (edo hutsa) baldin edozein estatutarako eta denbora guztirako akzio bat badago, non $\pi_{i, a}(t)=1$ baita eta gainontzeko akzioentzat, $\pi_{i, a^{\prime}}(t)=0$. 
Izan bedi $\mathbf{m}^{\pi}(t) \in \mathcal{P}(\mathcal{S})$ jokalarien banaketa $t$ unean; estatu-espazioa finitua denez, $\mathbf{m}^{\pi}(t)$ bektore bat da, non haren $i$ konponentea (alegia $m_{i}^{\pi}(t)$ ), $i$ estatuan $t$ unean dauden jokalarien proportzioa den. Onartuko dugu hasierako baldintzak finkoak direla: alegia, $\mathbf{m}^{\pi}(0)=\mathbf{m}_{0}$. Beraz, jokalarien distribuzioa, edozein unetan $(t \geq 0)$, hurrengo ekuazioaren bidez defini daiteke:

$$
\dot{m}_{j}^{\pi}=\sum_{i \in \mathcal{S}} \sum_{a \in \mathcal{A}} m_{i}^{\pi}(t) Q_{i j a}\left(\mathbf{m}^{\pi}(t)\right) \pi_{i, a}(t), \forall j \in \mathcal{S}
$$

Ekuazio honi erreparatzen badiogu, ikus daiteke jokalarien distribuzioa $\pi$ estrategiaren araberakoa dela (aurrerantzean $\pi$ estrategiari populazio-estrategia deituko diogu). Esan daiteke ezen, $a \in \mathcal{A}$ akzioa aukeratuz gero, $i$ estatuan dauden jokalariak $j$ estatura mugitzen direla $Q_{i j a}\left(\mathbf{m}^{\pi}(t)\right)$ tasarekin. Horiek horrela, $Q_{i j a}\left(\mathbf{m}^{\pi}(t)\right)$ matrize bat da, eta honako ekuazio hauek betetzen ditu:

$$
\sum_{j \in \mathcal{S}} Q_{i j a}\left(\mathbf{m}^{\pi}(t)\right)=0, \forall i \text { eta } \forall a
$$

eta

$$
Q_{i j a}\left(\mathbf{m}^{\pi}(t)\right) \geq 0, \forall j /=i \text {, eta } \forall a .
$$

Aurrera egin baino lehen, guk definitu dugun jokoaren ezaugarri garrantzitsu bat ikusiko dugu. Eredu honetan, $Q_{i j a}\left(\mathbf{m}^{\pi}(t)\right)$ matrizea jokalarien banaketaren araberakoa da. Batez besteko eremuko joko antzeko bat aztertu dute literaturan (ikusi esate baterako [4]). Hala ere, haien ereduek $Q_{i j a}\left(\mathbf{m}^{\pi}(t)\right)$ matrizea konstante dela jotzen dute; hau da, $Q_{i j a}\left(\mathbf{m}^{\pi}(t)\right)=Q_{i j a}$. Hori dela bide, gure eredua literaturan ikertutakoa baino orokorragoa dela baieztatzen dugu.

Jokalari bakar bat aztertuko dugu orain: jokalari horri 0-jokalari deritzo. Jokalari horrek bere estrategia aukeratzeko ahalmena du; $\pi^{0}$ estrategia: $\pi^{0}$ : $\mathbb{R} \times \mathcal{S} \rightarrow \mathcal{P}(\mathcal{A}) \cdot \mathbf{x}^{\pi^{0}}(t) 0$ jokalariaren probabilitate-distribuzioa da, $\pi^{0}$ estrategia aukeratzen duenean eta populazio-estrategia $\pi$ denean. $\mathbf{x}^{\pi^{0}}(t) \in \mathcal{P}(\mathcal{S})$. Beraz, $x_{i}^{\pi^{0}}(t)$ da 0 jokalariak $i$ estatuan $t$ unean egoteko duen probabilitatea $\mathrm{da} ; \mathbf{x}^{\tau^{0}}$ bektorea denborarekiko aldakorra da, ekuazio honen arabera:

$$
\dot{x}_{j}^{\pi^{0}}(t)=\sum_{i \in \mathcal{S}} \sum_{a \in \mathcal{A}} x_{i}^{\pi^{0}}(t) Q_{i j a}\left(\mathbf{m}^{\pi}(t)\right) \pi_{i, a}^{0}(t), \forall j \in \mathcal{S} .
$$

0 jokalariak, $i$ estatuan badago eta $a$ akzioa aukeratzen badu $t$ unean, $c_{i, a}(\mathbf{m} \pi(t))$ kostua izango du. Garrantzitsua da nabaritzea kostu hori $\mathbf{m}^{\pi}(t)$-ren araberakoa dela, hau da, jokalarien banaketaren araberakoa. Horrela, 0 joka- 
lariaren kostu totala edozein populazio-estrategiarako $(\pi)$ eta 0 jokalariaren edozein estrategiatarako $\left(\pi^{0}\right)$ hurrengo ekuazioaren bidez defini daiteke:

$$
V\left(\pi^{0}, \pi\right)=\int_{0}^{\infty}\left(\sum_{i \in \mathcal{S}} \sum_{a \in \mathcal{A}} x_{i}^{\pi^{0}}(t) \cdot c_{i, a}\left(\mathbf{m}^{\pi}(t)\right) \cdot \pi_{i, a}^{0}(t) \cdot e^{-\beta t}\right) d t
$$

non $\beta>0$ deskontu-faktorea den.

0 jokalariak guztizko kostu minimoa izatea du helburu, eta, horretarako, $\pi^{0}$ estrategia aukeratuko du; alegia, populazio-estrategia $\pi$ badela kontuan hartuz, 0 -jokalariak $\pi^{0}$ estrategia aukeratuko du bere kostu totala minimoa izateko. Hori egiten duenean, erantzunik hoberena $(\mathrm{EH})$ deritzon estrategia aukeratu duela esaten dugu. Honako ekuazio hau erabiliz defini daiteke erantzunik hoberena den estrategia:

$$
E H(\pi)=\underset{\pi^{0}}{\arg \min } V\left(\pi^{0}, \pi\right) .
$$

Ekuazio horrek adierazten du kostua minimizatzen duten funtzioen artean dagoela erantzunik hoberena.

Dagoeneko definitzen ahal dugu batez besteko eremuko oreka, hau da, batez besteko eremuko jokoaren soluzioa: populazio-estrategia $\pi^{B E O}$ izanik, 0 jokalari berekoiak $\pi^{B E O}$ estrategia aukeratzen duenean gertatzen da batez besteko eremuko oreka. Matematikoki horrela definitzen da:

Definizioa 1 (Batez besteko eremuko oreka). Esango dugu $\pi^{B E O}$ estrategia batez besteko eremuko oreka dela baldin erantzunik hoberena funtzioaren puntu finkoa bada; hau da,

$$
\pi^{B E O} \in E H\left(\pi^{B E O}\right) .
$$

Definizio hau argi gera dadin, azalpen txiki bat emango dugu. Demagun, populazioko jokalari guztiak berekoiak direla. Horiek horrela, erantzunik hoberena den estrategia aukeratuko dute, eta, homogeneoak direnez, 0 jokalariak hautatutako estrategia aukeratuko dute; beste era batean esanda, guztiek $E H(\pi)$ aukeratuko dute. Hots, populazio-estrategia eta erantzunik hoberenaren estrategia berdinak badira, populazioko jokalari guztiek kostu totala minimoa izango dute, eta, beraz, ez dute interesik aldebakarreko estrategia-aldaketa egiteko. Egoera hori oreka da.

\subsection{Orekaren existentzia}

Atal honen helburua da batez besteko eremuko oreka badagoela frogatzea. Horretarako, hipotesi hauek emango ditugu:

(H1) $\mathbf{m} \mapsto Q_{i j a}(\mathbf{m}) \quad$ eta $\quad \mathbf{m} \mapsto c_{i, a}(\mathbf{m})$ funtzioak jarraituak dira $\mathbf{m}$-rekin . 
Hipotesi horiei esker, esan dezakegu ondo definituak daudela (1) eta (2) ekuazioak, eta bai (3) kostua ere.

Kakutani-ren puntu finkoaren teorema erabiliko dugu gure emaitza frogatzeko. Autore batzuek ([5, 3] esate baterako) onartzen dute kostua funtzio konbexua dela, eta, beraz, $E H(\pi)$ funtzioak Kakutaniren teoremaren baldintzak betetzen dituela. Zoritxarrez, gure hipotesiak dio kostua funtzio jarraitua dela; beraz, Kakutaniren teoremaren baldintzak betetzen direla ikusteko, beste modu batean definitu behar dugu $E H(\pi)$ funtzioa. Frogapena ez dugu artikulu honetan sartu, baina interesa duen irakurleari [2] artikulua irakurtzea gomendatzen diogu.

Teorema 1. Definitutako edozein batez besteko eremuko jokok oreka bat du (H1) baldintza betez gero.

Frogapena ez dugu artikulu honetan sartu, toki falta dela eta. Hala ere, frogapenaren ideia azalduko dugu. Teorema hori frogatzeko, $E H(\pi)$ funtzioaren baliokidea den funtzio bat erabiltzen da, zeinak Kakutaniren teoremaren baldintzak betetzen baititu. Hortaz, $E H(\pi)$ funtzioak puntu finko bat duela ondoriozta daiteke.

\section{ONDORIOAK ETA ETORKIZUNEKO LANA}

Artikulu honetan, batez besteko eremuko jokoak aztertzen ditugu, zeinetan akzio-espazioa diskretua den. Lan honek arlo berri bat irekitzen lagunduko duela uste dugu. Izan ere, aurrean esan dugun bezala, kasu diskretuko batez besteko eremuari buruzko literatura oso urria da.

Lehendabizi, lan honetarako erabilitako literaturaren errebisioa egin dugu. Horrela, batez besteko eremuko jokoek duten garrantziaren arrazoia ikusi dugu. Artikuluaren bigarren zatian, gure ikerketan egindako adibide bat aurkeztu dugu, non denbora jarraitua dela jo dugun. Frogatu dugu oreka bat existitzen dela kasu partikular horretarako baldin eta hipotesi batzuk betetzen badira. Gainera, guk emandako baldintzak aurreko emaitzetan agertutakoak baino orokorragoak dira. Beraz, gure lana beste autore batzuena baino orokorragoa da.

Gure ikerketan beste zenbait kasu aztertu ditugu: esate baterako, denbora diskretua den eredua, edo denbora zerotik $\mathrm{T}$ une finitu batera heltzen den eredua. Kasu guztietan, orekaren existentzia frogatzea lortu dugu. Hala ere, espazio falta dela kausa, ez ditugu eredu horiek artikulu honetan sartu eta interesa duen irakurleari erreferentzietan dagoen artikulua irakurtzea gomendatzen diogu [2].

Etorkizunerako planteatzen den ikerketari dagokionez, zer? Gure ikerketan oreka bat existitzen dela frogatu dugu, baina ez dakigu oreka hori 
bakarra den ala ez. Literaturan orekaren bakartasunaren problema ikertu dute zenbait autorek antzeko ereduetan, eta haien emaitzek diote baldintza gehiago ezarri behar direla ereduan bakartasun hori ziurtatzeko. Ondo legoke ikertzea zein baldintzek ziurtatzen duten orekaren bakartasuna guk ikertutako ereduetan.

Etorkizunerako, halaber, interesgarria iruditzen zaigu ikertzea zer baldintza bete behar diren gure eredua hurbilketa ona izango bada. Izan ere, batez besteko eremuko jokoak joko finituen hurbilketak dira, baina ez dakigu konbergentzia-tasa nolakoa den.

Aurrean esan dugun bezala, literatura gutxi dago kasu diskretuko batez besteko jokoen inguruan. Hori dela eta, ikerketa asko ere egin daiteke arlo honetan, eta, aipatu ditugunez gain, beste ideia asko ere azter daitezkeela uste dugu.

\section{ESKERRAK ETA OHARRAK}

Josu Doncel Vicentek Inria laborategian egindako doktoretza ondorengo ikerketaren zati bat da lan hau. Emaitzen frogapenak eta ereduaren xehetasun guztiak hurrengo txosten teknikoan agertzen dira [2]. Egileak N. Gast-ek (Inria), B. Gaujal-ek (Inria) eta U. Ayesta-k (IRIT-CNRS eta Ikerbasque-UPV/EHU) emandako laguntza teknikoa eskertzen du.

\section{BIBLIOGRAFIA}

[1] DASKALAKIS, CONSTANTINOS, GOLDBERG, PAUL W eta PAPADIMITRIOU, CHRISTOS H. «The complexity of computing a nash equilibrium». SIAM Journal on Computing 39:195-259.

[2] DONCEL, JOSU, GAST, NICOLAS eta GAUJAL, BRUNO. «Mean-Field Games with Explicit Interactions». Txosten Teknikoa. Hemen ikusgai: https://hal.inria.fr/hal-01277098

[3] GOMES, DIOGO, MOHR, JOANA eta SOUZA, RAFAEL RIGÃO. 2013. «Continuous Time Finite State Mean Field Games». Applied Mathematics \& Optimization, 68(1):99-143.

[4] GOMES, DIOGO, MOHR, JOANA eta SOUZA, RAFAEL RIGAO. 2010. «Discrete time, finite state space mean field games». Journal de Mathématiques Pures et Appliquées, 93(3):308-328.

[5] GOMES, DIOGO eta PIMENTEL, EDGARD A. 2015. «Regularity for mean-field games systems with initial- initial boundary conditions: The subquadratic case». In Dynamics, Games and Science, pages 291-304. Springer.

[6] GAST, NICOLAS, GAUJAL, BRUNO eta LE BOUDEC, JEAN-YVES. 2012. «Mean field for Markov Decision Processes: from Discrete to Continuous Optimization». IEEE Transactions on Automatic Control, 57:2266-2280. 
[7] LASRY, JEAN-MICHEL eta LIONS, PIERRE-LOUIS. 2006. «Jeux a champ moyen. ile cas stationnaire». Comptes Rendus Mathematique. 343:619-625.

[8] LASRY, JEAN-MICHEL eta LIONS, PIERRE-LOUIS. 2016. «Jeux a champ moyen. IIHorizon fini et controle optimal». Comptes Rendus Mathematique. 343.679-684.

[9] LASRY, JEAN-MICHEL eta LIONS, PIERRE-LOUIS. 2017. «Mean field games». Japanese Journal of Mathematics. 2:229-260.

[10] NASH, JOHN. 1951. «Non-cooperative games». Annals of Mathematics. 54:286-295.

[11] PUTERMAN, MARTIN L. 2014. «Markov decision processes: discrete stochastic dynamic programming». John Wiley \& Sons. 